\title{
ЯЗЫКОЗНАНИЕ
}

\section{Пространственная семантика послелога деер в калмыцком языке}

\section{Людмила Алексеевна Лиджиева ${ }^{1}$, Бамба Эрендженовна Убушиева ${ }^{2}$, Жанна Алексеевна Мукабенова}

${ }^{1}$ Калмыцкий государственный университет имени Б. Б. Городовикова (д. 11, ул. А. С. Пушкина, 358000 Элиста, Российская Федерация) кандидат филологических наук, доцент

iD 0000-0003-4262-5458. E-mail: lidzhieva-la@mail.ru

2 Калмыцкий государственный университет имени Б. Б. Городовикова (д. 11, ул. А. С. Пушкина, 358000 Элиста, Российская Федерация) кандидат филологических наук, доцент

iD 0000-0003-1895-2897. E-mail: ubamba@yandex.ru

${ }^{3}$ Калмыцкий государственный университет имени Б. Б. Городовикова (д. 11, ул. А. С. Пушкина, 358000 Элиста, Российская Федерация) старший преподаватель

iD 0000-0002-7527-7990. E-mail: zhanna61297@yandex.ru

(C) КалмНЦ РАН, 2020

(С) Лиджиева Л. А., Убушиева Б. Э., Мукабенова Ж. А., 2020

Аннотация. Введение. Настоящая статья посвящена пространственным употреблениям послелога деер в калмыцком языке. В семантической системе послелогов, образующих послеложные конструкции, открывается сложная область различных отношений. Особое место в монгольских языках занимают пространственные значения послелогов. Послелог деер - один из распространенных и продуктивных послелогов в монгольских языках. Целью исследования является описание пространственных значений послелога деер в калмыцком языке. Материалом исследования послужили данные, выбранные из различных словарей, художественных и публицистических текстов, находящихся в Национальном корпусе калмыцкого языка, Калмыцкого национального корпуса, Калмыцкой электронной библиотеки. Результаты исследования. Данный послелог отмечен во всех словарях монгольских языков и является одним из распространенных и продуктивных послелогов. Выражает самые разнообразные отношения, вытекающие из его синтаксических связей: пространственные, временные, комитативные, целевые, количественно-ограничительные значения. Наряду с конкретными, реальными отношениями данный послелог в различных речевых ситуациях приобретает дополнительные, иногда весьма абстрактные значения, отталкиваясь от своего основного значения. Подробно рассмотрены пространственные значения послелога деер в калмыцком языке. Помимо своего основного значения — расположения или движения 
на поверхности, данный послелог обозначает движение или совершение действия над поверхностью объекта без достижения контакта, возле, около ориентира, а также показывает направленность действия. Этот послелог может выражать «событийное пространство». Bblвoдbl. Анализ пространственных отношений, выражаемых послелогом деер, показал многообразие передаваемых значений в различных речевых ситуациях, а также особенности его употребления в калмыцком языке.

Ключевые слова: пространственные отношения, послелоги, средства выражения, калмыцкий язык

Благодарность. Исследование выполнено при финансовой поддержке РФФИ в рамках научного проекта № 20-012-00551 «Категория пространства в монгольских языках: типология и диахрония» и внутривузовского гранта Калмыцкого государственного университета в рамках проекта «Монгольское и тюркское языкознание: традиции и инновации». Материалы статьи апробированы на Международной научной онлайн-конференции «Монголоведение в начале XXI в.: современное состояние и перспективы развития - II», проведенной при финансовой поддержке РФФИ (проект № 20-09-22004) и частичной поддержке гранта Правительства РФ (№ 075-15-2019-1879).

Для цитирования: Лиджиева Л. А., Убушиева Б. Э., Мукабенова Ж. А. Пространственная семантика послелога деер в калмыцком языке // Монголоведение. 2020. Т. 12. № 4. C. 605-614. DOI: 10.22162/2500-1523-2020-4-605-614

UDC 811.512 .37

DOI: $10.22162 / 2500-1523-2020-4-605-614$

\title{
Postposition deep in the Kalmyk Language: Spatial Semantics
}

\author{
Liudmila L. Lidzhieva1, Bamba E. Ubushieva2, Zhanna A. Mukabenova ${ }^{3}$ \\ ${ }^{1}$ Gorodovikov Kalmyk State University (11, Pushkin St., Elista 358000, Russian Federation) \\ Cand. Sc. (Philology), Associate Professor \\ iD 0000-0003-4262-5458. E-mail: lidzhieva-la@mail.ru
}

${ }^{2}$ Gorodovikov Kalmyk State University (11, Pushkin St., Elista 358000, Russian Federation) Cand. Sc. (Philology), Associate Professor

iD 0000-0003-1895-2897. E-mail: ubamba@yandex.ru

${ }^{3}$ Gorodovikov Kalmyk State University (11, Pushkin St., Elista 358000, Russian Federation) Senior Lecturer

iD 0000-0002-7527-7990. E-mail: zhanna61297@yandex.ru

(C) KalmSC RAS, 2020

(C) Lidzhieva L. A., Ubushieva B. E., Mukabenova Zh. A., 2020

Abstract. Introduction. The article examines spatial uses of the postposition deep in the
Kalmyk language. The semantic system of postpositions that form postpositional constructions
comprises a complex area of various relations. A remarkable place in the Mongolic languages
is occupied by spatial meanings of postpositions, the postposition deep being a most common
and productive one therein. Goals. The research aims to describe spatial meanings of the
postposition deep in the Kalmyk language. Materials. The work analyzes data selected
from various dictionaries, literary and journalistic texts included in the National Corpus of 
the Kalmyk Language, Kalmyk National Corpus, and the Kalmyk Digital Library. Results. This postposition is mentioned in all dictionaries of Mongolic languages and is a most common and productive lexical unit. It expresses a wide variety of relations resulting from its syntactic ties: spatial, temporal, comitative, target, and quantitative-restrictive values. Along with concrete, real relations this postposition in various speech situations acquires additional, sometimes very abstract meanings based its core seme. The spatial meanings of the postposition deep in the Kalmyk language are considered in detail. In addition to its main meaning - location or movement on the surface - this postposition indicates movement or performing an action over the surface of an object without reaching contact, in close vicinity, near a landmark, and also shows the direction of action. This postposition can express 'event space'. Conclusions. The analysis of spatial relations expressed by the postposition deep shows a variety of transmitted meanings in various speech situations, as well as features of its use in the Kalmyk language.

Keywords: spatial relations, postpositions, means of expression, Kalmyk language

Acknowledgements. The reported study was funded by RFBR, project no. 20-012-00551 'The Category of Space in the Mongolic Languages: Typology and Diachrony', and Gorodovikov Kalmyk State University, research grant project 'Mongolic and Turkic Linguistics: Traditions and Innovations. The article was presented at the International scientific online conference 'Mongolian Studies at the Beginning of the $21^{\text {st }}$ Century: Current State and Development Prospects - II' funded by RFBR (project no. 20-09-22004) and Government of Russia (grant no. 075-15-2019-1879).

For citation: Lidzhieva L. L., Ubushieva B. E., Mukabenova Zh. A. Postposition deep in the Kalmyk Language: Spatial Semantics. Mongolian Studies (Elista). 2020. Vol. 12. No. 4. Pp. 605-614. (In Russ.). DOI: 10.22162/2500-1523-2020-4-605-614

\section{Введение}

Известно, что для монгольских языков характерно широкое употребление послелогов. В семантической структуре данных служебных слов, образующих послеложные конструкции, наблюдается сложная область различных отношений, выражающих понимание самых разнообразных связей между предметами, состояниями и действиями в реальной действительности.

Пространственные отношения являются наиболее значимыми для языка. Каждый язык выработал целый набор определенных лексических и морфологических средств отражения окружающего нас пространства (существительные, прилагательные, наречия, послеложные конструкции, местоимения, глаголы, глагольные формы и др.). По замечанию О. Н. Селиверстовой, «каждый язык располагает средствами интерпретировать одну и ту же ситуацию сознания множеством разнообразных способов. Центральной задачей лингвистики является изучение этих средств и их функций» [Селиверстова 1982: 13]. Таким образом, в каждом языке существует специфическая система обозначения направления движения или местонахождения предмета.

В монгольских языках пространственные отношения рассматривались в связи с изучением послеложных конструкций, глаголов движения, семантики падежных форм [Пюрбеев 1993; Трофимова 1989; Бадмаев 2002; Харчевникова 2006; Шойжонова 2007; Убушиева 2013; Лиджиева 2017] и др.

Системе многих языков характерна многозначность послелогов. Это связано с тем, что «семантические объемы их семем перегружены, и это является 


\section{Монголоведение • Mongolian Studies • 2020 ๑ T. 12 • № 4}

причиной образования в языке новых единиц — производных послелогов или их функциональных аналогов, первоначально однозначных, и лишь в течение длительного функционирования становящихся ... многозначными» [Лиджиева 2017: 23].

В данной статье рассматривается пространственная семантика многозначного послелога деер в калмыцком языке. Это один из распространенных и продуктивных послелогов в монгольских языках, который выражает самые разнообразные отношения, вытекающие из его синтаксических связей: пространственные, временные, комитативные, целевые, количественно-ограничительные значения. Наряду с конкретными, реальными отношениями данный послелог в различных речевых ситуациях приобретает дополнительные, иногда весьма абстрактные значения, отталкиваясь от своего основного значения. Материалом исследования послужили данные, извлеченные из избранных старописьменных памятников, различных словарей, а также национальных корпусов калмыцкого языка и калмыцкой электронной библиотеки.

\section{Пространственные значения послелога деер}

В «Этимологическом словаре монгольских языков» отмечается наличие данного послелога в следующих монгольских языках: degere (*dege-re) халх. дээр, бур. дээрэ, калм. деер, бао. дэқон, даг. дэр, дунс. джіэрэ, мнгр. дере 'наверху, высоко; на; лучше' [ЭСМЯ, I 2015: 180].

По мнению Г. Д. Санжеева, «наречие-послелог дегере представляет собою образование от омертвелого ныне корня деге- плюс -ре, т. е. элемент, входящий в состав указательного местоимения тере 'тот' и ряда наречий-послелогов: доура ‘внизу', джагура ‘в пути' и др. [Санжеев 1953: 221].

Данный послелог отмечен во всех словарях монгольских языков [Ramstedt 1935; Позднеев 1911; БАМРС, 2 2001; КРС 1977; БРС, 1 2010; и др.]. Например: mörn dēr’ qarxa 'садиться на коня' "[Ramstedt 1935: 91]; nüčüken yazar dère bičigei kebte 'не лежи на голой земле' [Позднеев 1911: 68]; čotoni noyon ger dēreni irebe ‘Цотон нойон пришел к дому' [Позднеев 1911: 140]; монг. зам дээр буув 'остановился у дороги' [БАМРС, 2 2001: 118].

В старописьменных памятниках он встречается в значениях местонахождения на поверхности, а также указывает направленность действия на поверхность предмета. Например:

- среднемонг. dabaan deere nikan hulaan deeltu eme kuun 'На перевале (стояла) женщина в красном халате' [CС 1941: 240, § 146]; Bekter huldun deere širqa aqtatan yesun mori qaraju 'Бектер в это время стерег на холме девять соловых меринов’ [CC 1941: 213, § 77]; nikan udur Duwa-Soqor Dobun-Merkan deu-luebeen Burqan-qaldun deere qarba 'Однажды Дува-Сохор, вместе со своим младшим братом Добун-Мергеном, взобрался на Бурхан-халдун' [СС 1941: 203, $\S 5]$;

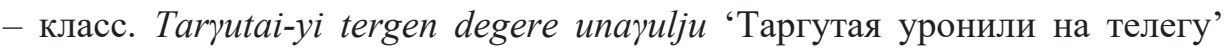
[AT 1992: 50, 1616-1617]; tayičijud Onan-u ergi degere qurimlalduju naran šinggebesü ele tarqabai 'Тайдчиудцы праздновали веселым пиршеством на крутом берегу Онона и разошлись, когда уже зашло солнце' [АТ 1992: 14, 586-

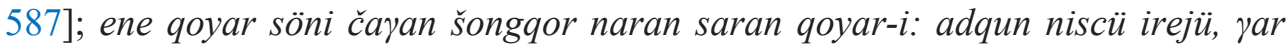

\footnotetext{
1 Здесь и далее перевод авторов.
} 


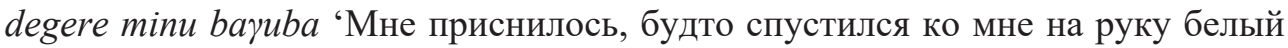
сокол, зажавший в когтях солнце и руку’ [АТ 1992: 10, 429-430].

Подробно остановимся на пространственных значениях послелога деер в калмыцком языке, который управляет именительным падежом.

I. Первое значение послелога деер связано с местонахождением на поверхности

а) нахождение объекта на горизонтальной поверхности (контактное расположение):

(1) Герин маштг кирлизн деер дөрвн, тавһ күүкд баглрад сууихажч.

$\begin{array}{lllll}\text { Гер=ин } & \text { маштг } & \text { кирлцән } & \text { деер } & \text { дөрвн, } \\ \text { Дом-Gen } & \text { низкий-Adj } & \text { крыльцо-Nom } & \text { на-Post } & \text { четыре-Num } \\ \text { тавн } & \text { күн } & \text { баглр-ад } & \text { суу-цха-ж. } & \\ \text { пять-Num } & \text { человек-Nom } & \text { собираться-Cvb.Ant } & \text { сидеть-Plr-Evd. }\end{array}$

'На низком крыльце дома сидели четыре-пять человек'.

[НККЯ: Эрнжәнә Константин. Һалан хадһл]

б) нахождение объекта на вертикальной поверхности (контактное расположение):

(2) Гер дотр, ордг Үүдна хажууд, эрс деер телефон өлгәтә билә.

$\begin{array}{lllll}\text { Гер } & \text { дотр, } & \text { ор-дг } & \text { Үүдн-ә } & \text { хажуд, } \\ \text { Дом-Nom } & \text { в-Post } & \text { входить-Ptcp.Hab } & \text { дверь-Gen } & \text { возле-Post } \\ \text { эрс } & \text { деер } & \text { телефон } & \text { өлг-әтә } & \text { билә. } \\ \text { стена-Nom } & \text { на-Post } & \text { телефон-Nom } & \text { вешать-Ptcp.Pass } & \text { быть-Rem. }\end{array}$

'В доме, возле двери, на стене висит телефон'.

[КНК: Илүмжин Николай. Ө-шуһу модна һазрт]

в) в калмыцком языке данный послелог может выражать значение нахождения объекта в большом размере пространства. При этом, по словам О. Н. Селиверстовой, «обнаруживается допустимость разного осмысления денотатов таких слов, как небо, море, океан, болото, поле» [Селиверстова 2000: 196]. Из данного примера видно, что нет определенных требований к небу как плоскости или объему:

(3) Тенцгр деер, хол, түмн оддуд гилвкнд.

$\begin{array}{lll}\text { Теңгр } & \text { деер, } \quad \text { хол, } & \text { түмн } \\ \text { Небо-Nom } & \text { на-Post } \quad \text { далеко-Adv } & \text { десять тысяч-Num } \\ \text { од-д-уд } & \text { гилвк-нә. } & \\ \text { звезда-P1 } & \text { светиться-Prs. }\end{array}$

'На небе, далеко, сияют множество звезд'.

[КЭБ. Сусен Аксен. Теегин үрн]

II. Послелог деер указывает на место совершения действия

a) совершение действия или движение в пространстве на горизонтальной поверхности с достижением контакта:

(4) Хаалһ деер дөрвн хурдн мөрн көндрв.

$\begin{array}{llll}\text { Хаалh } & \text { деер } & \text { дөрвн } & \text { хурдн } \\ \text { Дорога-Nom } & \text { на-Post } & \text { четыре-Num } & \text { быстрый-Adj }\end{array}$




\section{Монголоведение • Mongolian Studies • $2020 \bullet$ T. 12 • № 4}

мөрн

лошадь-Nom көндр-в.

двигаться-Pst.

'По дороге движутся четыре быстрые лошади'.

[КЭБ. Сусен Аксен. Шин жирһл угтад]

б) движение на поверхности, где объектом выступают географические названия - уул 'гора', хад ‘скала', толһа 'курган', өөдм 'возвышенность' и т. п.: (5) Энд һол талви бәәнд, уул деер бумб тәвгджс:

$\begin{array}{llll}\text { Эн-д } & \text { hол } & \text { талвң } & \text { бәә-нә, } \\ \text { Здесь-Pron-Dat } & \text { главный-Adj } & \text { площадь-Nom } & \text { быть-Pst } \\ \text { уул } & \text { дее } & \text { бумб } & \text { тәв-гд-ж. } \\ \text { гора-Nom } & \text { на-Post } & \text { памятник-Nom } & \text { ставить-Pass-Evd. }\end{array}$

'Здесь находится главная площадь, на горе поставили памятник'.

[КНК: Хальмг үнн]

в) движение объекта над определенной поверхностью (отсутствие контакта). Локализуемый объект занимает позицию выше ориентира, показывая при этом отсутствие контакта. При этом необязательно, чтобы поверхность являлась плоским объектом:

(6) Мамайин өөдм деер утан ияоонрад, тенцгиг кевтнь бүтәчксн бәәнд.

Мамай-ин

Мамай-Gen

цоонгр-ад

подниматься вверх-Cvb.Ant

бүт-ә-чк-сн

заполняться-Caus-Compl-Ptcp.Pst становиться-Prs.

'Над Мамаевым курганом дым, поднявшись вверх, полностью заполнил небо'.

[КНК: Илүмжин Николай. Абиль]

г) движение или совершение действия около ориентира:

(7) Хөд оңңһи деер улм дариад-хәргәд бәәнд.

Хө-д

Овца-P1

оңһц

корыто-Nom

деер

возле-Post

улм

дарц-ад-хәрг-әд

бәә-нә.

толпиться--Cvb.Ant-давиться-Cvb.Ant быть-Pst деер утан

над-Post дым-Nom

кевтнь

целиком-Adv

'Овцы у корыта стали еще сильнее давиться' .

[КЭБ. Манжин Нимгр. Ик герин бичкн эзн]

\section{III. Направленность действия относительно ориентира}

a) направленность на верхнюю сторону ориентира (горизонтальную поверхность) с достижением контакта:

(8) Умилч, гиһдд Батан өөрк диван деер суув.

\begin{tabular}{llll} 
Умш-л-ч, & гиһ-әд & \multicolumn{1}{|c}{ Бата-н } \\
Читать-Imp-Part.Emph-Per2Part & говорить-Cvb.Ant & Бата-Gen \\
өөр-к & диван & деep & суу-в. \\
находящийся возле-Post & диван-Nom & на-Post & сидеть-Pst
\end{tabular}

'Прочитай-ка, сказав так, [он], он сел на диван, находящийся возле Баты'.

[КНК: Эрнжәнә Константин. Һалан хадһл] 
б) направленность на поверхность объекта (не обязательно плоский):

(9) Уульин ора деер һарч харвв.

Уул-ын ора дер иар-ч хар-в.

Гора-Gen вершина-Nom на-Post выходить-Cvb.Ipfv смотреть-Pst.

'Взобравшись на вершину горы, (он) стал пристально смотреть'.

[KPC 1977: 400]

в) направленность к определенному объекту:

(10) ... үкрмүд гер деер күрч ирв

... үкр-мүд гер деер күр-ч ир-в.

Корова-Pl дом-Nom к-Post доходить-Cvb.Ipfv приходить-Pst

‘... коровы пришли домой (к дому)'.

[КЭБ. Манжин Нимгр. Ик герин бичкн эзн]

IV. Отдельно следует отметить значение послелога деер, которое обозначает «событийное пространство» [Селиверстова 2000: 200]. В данном случае отмечаются представления о площадках, где распределены объекты, связанные с описываемым пространством, например на базаре, станции, собрании, встрече и т. д.

(11) Альк базр деер эн зәңฺг келв?

$\begin{array}{llll}\text { Альк } & \text { базр } & \text { деер } & \text { эн } \\ \text { Какой-Pron } & \text { базар-Nom } & \text { на-Post } & \text { этот-Pron } \\ \text { зәңг } & \text { кел-в? } & & \\ \text { новость-Aсс } & \text { говорить-Pst? } & & \end{array}$

'На каком базаре сказали эту новость?'.

[НККя: Эрнжәнә Константин. Һалан хадһл]

(12) Олна хург деер хәләх төрмүд хаһлгдв.

Олн-а хург

Много-Gen собрание-Nom на-Post смотреть-Ptcp.Fut

төр-мүд $\quad$ хаһл-гд-в.

тема-Pl решать-Pass-Pst.

'На общем собрании были рассмотрены поставленные проблемы'.

[КЭБ: Нармин Морхаж. Манц һол]

Также в калмыцком языке значение данного пространства может соотноситься со словами хотн 'хотон', балһсн 'город'. Так как населенные пункты ассоциируются с закрытым, внутренним пространством, то послелог деер выступает в значении 'в, внутри'.

(13) Балһсн деер көдлдг орм уга болву?

$\begin{array}{llllll}\text { Балһсн } & \text { деер } & \text { көдл-дг } & \text { орм } & & \\ \text { Город-Nom } & \text { в-Post } & \text { работать-Ptcp.Наb } & \text { место-Nom } & \text { уга } & \text { бол-в-у? } \\ & & & & \text { Нет-Neg } & \text { быть-Pst-Q? }\end{array}$

'В городе не было работы?'.

[КЭБ: Бадмин Алексей. Усна экн - булг] 


\section{Монголоведение • Mongolian Studies • 2020 ๑ T. 12 • № 4}

(14) Нег циагт, ик кезәнд, мана хотн деер тиим догшн аюл болсн юмн.

\begin{tabular}{llll} 
Нег & цаг-т, & \multicolumn{3}{c}{ ик } & \multicolumn{1}{c}{ кезәнә, } & \\
Один-Num & время-Dat & большой-Adj & давно-Adv \\
ма-на- & хотн & деep & тиим \\
Я-Gen & хотон-Nom & в-Post & такой-Pron \\
догшн & аюл & болсн & юмн. \\
свирепый-Adj & стихия-Nom & становиться-Ptcp.Pst & есть-Part.Aff. \\
'Однажды, очень давно, в нашем хотоне была такая стихия'.
\end{tabular}

[НККЯ: Сән-Белгин Хаср. Дурн болн дун]

\section{Заключение}

Функциональная дистрибуция послелога деер в калмыцком языке обнаруживает разнообразие и многозначность пространственных отношений. Наряду с конкретными, реальными значениями, данный послелог в различных речевых ситуациях приобретает дополнительные, отталкиваясь от своего основного значения. Основное значение послелога связано с нахождением на поверхности (горизонтальной, вертикальной), где прослеживаются отсутствие или наличие контакта. Совершение действия отмечается не только на поверхности, но и над определенным пространством (бесконтактное движение), а также около, возле определенного ориентира. Отдельно выделены значения направленности действия. Отмечается наличие значений, которые связаны с «событийным пространством».

\section{Сокращения}

бао. - баоаньский, бур. - бурятский, даг. - дагурский, дунс. - дуньсянский, калм. - калмыцкий, класс. - классический монгольский, мнгр - монгорский, среднемонг. - среднемонгольский, халх. - халхасский

Acc - аккузатив, Adj - прилагательное, Adv — наречие, Caus - каузатив (побудительный залог), Compl — законченный вид, Cvb.Ant - разделительное деепричастие, Cvb.Ipfv - соединительное деепричастие, Dat - датив, Evd прошедшее результативное время, Gen — генитив, Imp — императив, Neg отрицание, Nom - номинатив, Num - числительное, Part - частица, Part. Emph - усилительная частица, Part.Aff - подтвердительная частица, Pass - пассив (страдательный залог), Per2Part - лично-предикативная частица 2-го лица ед. ч., $\mathrm{Pl}$ — множественное число, Plr - глагольная множественность, Post - послелог, Pron - местоимение, Prs — настоящее время, Pst — недавнопрошедшее время, Ptcp.Fut - причастие будущего времени, Ptcp.Наb — многократное причастие, Ptcp.Pass - страдательное причастие, Ptcp.Pst - причастие прошедшего времени, $\mathrm{Q}$ - вопросительная частица, Rem - преждепрошедшее время

\section{Источники}

AT 1992 - Hans. Petet Vietze, Gendeng Lubsang. Altan Tobči. Text und Index. Tokyo: Institute for the Study of Languages and Cultures of Asia and Africa, 1992. 278 p.

НККЯ - Национальный корпус калмыцкого языка [электронный ресурс] // URL: http://kalmcorpora.ru/ (дата обращения: 25.08.2020).

КНК - Калмыцкий национальный корпус [электронный ресурс] // URL: http://webcorpora.net /(дата обращения: 25.08.2020).

КЭБ - Калмыцкая электронная библиотека [электронный ресурс] // URL: http:// halmglib.org/ (дата обращения: 25.08.2020). 
СС 1941 - Козин С. А. Сокровенное сказание: Монгольская хроника 1240 г. под

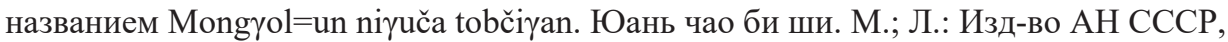
$1941.620 \mathrm{c}$.

\section{Sources}

Kalmyk Digital Library. Available at: http://halmglib.org/ (accessed: August 25, 2020). (In Kalm.)

Kalmyk National Corpus. Available at: http://web-corpora.net / (accessed: August 25, 2020). (In Kalm.)

Kozin S. A. The Secret History of the Mongols: Mongolian Chronicle of 1240 Titled

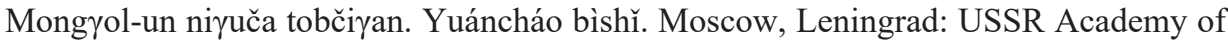
Sciences, 1941. 620 p. (In Russ.)

National Corpus of the Kalmyk Language. Available at: http://kalmcorpora.ru/ (accessed: August 25, 2020). (In Kalm.)

Vietze H.-P., Lubsang G. Altan Tobči. Text und Index. Tokyo: Institute for the Study of Languages and Cultures of Asia and Africa, 1992. 278 p. (In Eng.)

\section{Литература}

Ramstedt 1935 - Ramstedt G. J. Kalmückisches Wörterbuch. Helsinki: SuomalaisUgrilainen Seura, 1935. xxx $+560 \mathrm{~s}$.

Бадмаев 2002 - Бадмаев Б. В. Проблема служебных частей речи в современном калмыцком языке: послелоги // Вопросы теоретической грамматики калмыцкого языка. Сб. науч. ст. Вып. 1. М.; Элиста: Изд-во Калм. ун-та, 2002. С. 90-112.

БАМРС, 22001 - Большой академический монгольско-русский словарь. В 4 т. Т. 2. M.: ACADEMIA, 2001. $536 \mathrm{c}$.

БРС, 12010 - Шагдаров Л. Д., Черемисов К. М. Бурятско-русский словарь. В 2 т. Т. 1. Улан-Удэ: Изд-во АОА «Республиканская типография», 2010. 636 с.

КРС 1977 - Калмыцко-русский словарь / под ред. Б. Д. Муниева. М.: Русский язык, 1977. $768 \mathrm{c}$.

Лиджиева 2017 - Лиджиева Л. А. Послелоги калмыцкого языка в историкосопоставительном освещении. Элиста: Изд-во Калм. ун-та, 2017. 143 с.

Позднеев 1911 - Позднеев А. М. Калмыцко-русский словарь. Спб.: Тип. Имп. Акад. наук, 1911. $306 \mathrm{c.}$

Пюрбеев 1993 - Пюрбеев Г. Ц. Историко-сопоставительные исследования по грамматике монгольских языков. Синтаксис словосочетания. М.: Наука, 1993. $304 \mathrm{c}$.

Санжеев 1953 - Санжеев Г. Д. Сравнительная грамматика монгольских языков. Т. 1. М.: Изд-во АН СССР, 1953. 241 с.

Селиверстова 1982 - Селиверстова О. Н. Предикаты «нахождения в пространстве» // Сематические типы предикатов. М.: Наука, 1982. С. 146-151.

Селиверстова 2000 - Селиверстова О. Н. Семантическая структура предлога на // Исследования п〉о семантике предлогов. М.: Русские словари, 2000. С. 189-242.

Трофимова 1989 - Трофимова С. М. Падежно-послеложные конструкции монгольских языков и их русские эквиваленты. Новосибирск: Наука, 1989. 95 с.

Убушиева 2013 - Убушиева Б. Э. Лексика калмыцких народных песен (когнитивносемантический аспект): автореф. дис. ... канд. филол. наук. Элиста, 2013. 27 с.

Харчевникова 2006 - Харчевникова Р. П. Функциональный аспект исследования категории падежа в современном калмыцком языке // Вопросы теоретической грамматики калмыцкого языка. Сб. науч. ст. Вып. 2. М.; Элиста: Изд-во Калм. унта, 2006. C. 45-65.

Шойжонова 2007 - Шойжонова Д. Б. Послелоги и послеложные слова в современном бурятском языке: автореф. дис. ... канд. филол. наук. Улан-Удэ, 2007. 29 с. 
ЭСМЯ, 12015 - Санжеев Г. Д., Орловская М. Н., Шевернина 3. В. Этимологический словарь монгольских языков: в 3 т. Том I. А-Е. / гл. ред. Г. Д. Санжеев; ред. Л. Р. Концевич, В. И. Рассадин, Я. Д. Леман. М.: ИВ РАН, 2015. 224 с.

\section{References}

Badmaev B. V. Auxiliary parts of speech in modern Kalmyk: postpositions. In: Tenishev E. R. (ed.) Issues of Kalmyk Theoretical Grammar. Collected Scholarly Articles. Vol. 1. Moscow, Elista: Kalmyk State University, 2002. Pp. 90-112. (In Russ.)

Kharchevnikova R. P. Investigating the category of case in modern Kalmyk: functional aspect. In: Kharchevnikova R. P., Esenova T. S., Badmaev B. V. (eds.) Issues of Kalmyk Theoretical Grammar. Collected Scholarly Articles. Vol. 2. Moscow, Elista: Kalmyk State University, 2006. Pp. 45-65. (In Russ.)

Lidzhieva L. A. Kalmyk Postpositions: A Comparative Historical Perspective. Elista: Kalmyk State University, 2017. 143 p. (In Russ.)

Muniev B. D. (ed.) Kalmyk-Russian Dictionary. Moscow: Russkiy Yazyk, 1977. 768 p. (In Kalm. and Russ.)

Pozdneev A. M. Kalmyk-Russian Dictionary. St. Petersburg: Imperial Academy of Sciences, 1911. 306 p. (In Kalm. and Russ.)

Pyurbeev G. Ts. Comparative Historical Studies of Mongolic Grammars: Syntax of Word Combinations. Moscow: Nauka, 1993. 304 p. (In Russ.)

Luvsandendev A., Pyurbeev G. Ts. (eds.) Unabridged Academic Mongolian-Russian Dictionary. In 4 vols. Vol. 2. Moscow: Academia, 2001. 536 p. (In Mong. and Russ.)

Ramstedt G. J. Kalmückisches Wörterbuch (A Dictionary of Kalmyk). Helsinki: Finno-Ugric Sociaety, 1935. XXX + 560 p. (In Kalm. and Germ.)

Sanzheev G. D. Comparative Grammar of Mongolic Languages. Vol. 1. Moscow: USSR Academy of Sciences, 1953. 241 p. (In Russ.)

Sanzheev G. D., Orlovskaya M. N., Shevernina Z. V. Etymological Dictionary of Mongolic Languages. In 3 vols. Vol. I: A - E. G. Sanzheev et al. (eds.). Moscow: Institute of Oriental Studies (RAS), 2015. 224 p. (In Mong. and Russ.)

Seliverstova O. N. Predicates of 'spatial locations'. In: Seliverstova O. N. Sematic Types of Predicates. Moscow: Nauka, 1982. Pp. 146-151. (In Russ.)

Seliverstova O. N. Semantic structure of the preposition на. In: Paiar D., Seliverstova O. N. (eds.) Studies in Semantics of Prepositions. Moscow: Russkie Slovari, 2000. Pp. 189242. (In Russ.)

Shagdarov L. D., Cheremisov K. M. Buryat-Russian Dictionary. In 2 vols. Vol. 1. Ulan-Ude: Respublikanskaya Tipografiya, 2010. 636 p. (In Bur. and Russ.)

Shoyzhonova D. B. Postpositions and Postpositional Lexemes in Modern Buryat. Cand.Sc. (philology) thesis abstract. Ulan-Ude, 2007. 29 p. (In Russ.)

Trofimova S. M. Mongolic Declensional-Postpositional Constructs and Their Russian Equivalents. Novosibirsk: Nauka, 1989. 95 p. (In Russ.)

Ubushieva B. E. Vocabulary of Kalmyk Folk Songs: A Cognitive-Semantic Aspect. Cand. Sc. (philology) thesis abstract. Elista, 2013. 27 p. (In Russ.) 